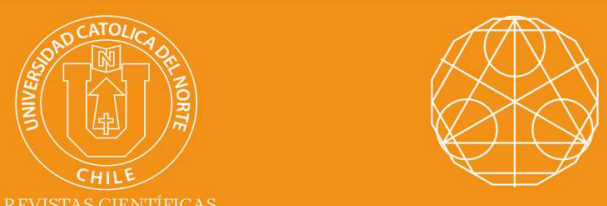

\title{
Some fixed point theorems for generalized Kannan type mappings in $b$-metric spaces
}

Nehjamang Haokip* (iD orcid.org/0000-0002-2307-4497

Nilakshi Goswami* $^{* *}$

*Gauhati University, Dept. of Mathematics, Guwahati, AS, India.

mark02mm@yahoo.co.in

${ }^{* *}$ Gauhati University, Dept. of Mathematics, Guwahati, AS, India

nila_g2003@yahoo.co.in

Received: July 2018 | Accepted: August 2018

\section{Abstract:}

In this paper, we prove some fixed point theorems in b-metric spaces using subadditive altering distance function. Some of these results generalize many existing fixed point theorems for Kannan type mappings. The results are justified with suitable examples.

Keywords: $b$-metric space; Subadditive altering distance function; Kannan type mappings.

MSC (2010): 47H10, 54E50.

\section{Cite this article as (IEEE citation style):}

N. Haokip and N. Goswami, Some fixed point theorems for generalized Kannan type mappings in $b$-metric spaces", Proyecciones (Antofagasta, On line), vol. 38, no. 4, pp. 763-782, Oct. 2019, doi: 10.22199/issn.0717-6279-2019-04-0050. [Accessed dd-mmyyyy].

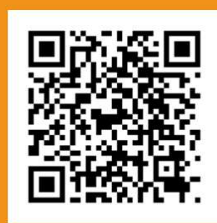

Article copyright: (C) 2019 Nehjamang Haokip and Nilakshi Goswami. This is an open access article distributed under the terms of the Creative Commons Licence, which permits unrestricted use and distribution provided the original author and source are credited. 


\section{Introduction}

One of the most prominent fixed point theorem since the famous "Banach contraction principle" [5] in 1922 is undeniably the Kannan fixed point theorem. It is a well known fact that every Banach contraction mapping is continuous. In 1968, Kannan [21] showed that a contractive mapping with a fixed point need not be necessarily continuous in proving the following result:

Theorem 1.1. [17] Let $(X, d)$ be a complete metric space and $T: X \longrightarrow$ $X$ be a mapping such that

$$
d(T x, T y) \leq k\{d(x, T x)+d(y, T y)\}
$$

for all $x, y \in X$ and $k \in[0,1 / 2)$. Then $T$ has a unique fixed point $z \in X$, and for any $x \in X$ the sequence of iterates $\left\{T^{n} x\right\}$ converges to $z$.

The importance of the above result lies in the fact that Kannan's theorem characterizes the completeness of the metric space. This was proved by Subrahmanyam [29] in 1975.

Theorem 1.1 is one of the several generalizations of the Banach contraction principle which were derived either by changing the contraction condition or by changing the space to a more generalized space (refer to [2], [10], [11], [12], [26], [30],among others). In this regard, Bakhtin [4] in 1989 introduced b-metric spaces to generalize Banach fixed point theorem. In 1993, Czerwik [9] formally defined the notion of b-metric spaces as follows.

Definition 1.1. [9] Let $X$ be a non empty set and $s \geq 1$ be a given real number. A function $d: X \times X \longrightarrow[0, \infty)$ is called $b$-metric if it satisfies the following properties.

1. $\quad d(x, y)=0$ if and only if $x=y$;

2. $\quad d(x, y)=d(y, x) ; \quad$ and

3. $\quad d(x, z) \leq s[d(x, y)+d(y, z)], \quad$ for all $\quad x, y, z \in X$.

The pair $(X, d)$ is called a $b$-metric space with coefficient $s$.

Since then many authors have generalized Banach fixed point theorem in $b$-metric spaces (refer to [1], [18], [19], [22], [23], [28] and the references therein). 
Example 1. It is evident from the definition that every metric is also a b-metric with coefficient 1. A few more examples (refer [6], [27]) are given below.

1. The set $l_{p}(\mathbf{R})=\left\{\left\{x_{n}\right\} \subset \mathbf{R}: \sum_{n=1}^{\infty}\left|x_{n}\right|^{p}<\infty\right\}$ with $0<p<1$, together with the function $d: l_{p}(\mathbf{R}) \times l_{p}(\mathbf{R}) \longrightarrow \mathbf{R}$ given by

$$
d(x, y)=\left(\sum_{n=1}^{\infty}\left|x_{n}-y_{n}\right|^{p}\right)^{\frac{1}{p}}
$$

is a $b$-metric space with coefficient $2^{\frac{1}{p}}$.

2. The set $L_{p}[0,1],(0<p<1)$ of all real functions $x(t), t \in[0,1]$ where $\int_{0}^{1}|x(t)| d t<\infty$ is a $b$-metric space with coefficient $2^{\frac{1}{p}}$ if we define the $b$-metric $d: L_{p}[0,1] \times L_{p}[0,1] \longrightarrow \mathbf{R}$ by

$$
d(x, y)=\left(\int_{0}^{1}|x(t)-y(t)|^{p} d t\right)^{\frac{1}{p}}
$$

3. Let $\left(X, d^{\prime}\right)$ be a metric space and define $d(x, y)=d^{\prime}(x, y)^{p}$, where $p>1$ is a real number. Then $(X, d)$ is a $b$-metric space with coefficient $2^{p-1}$.

It may be noted here that a $b$-metric need not be always continuous in the topology generated by it (refer Example 2.6 of [24]). Moreover, the notion of convergent sequence, Cauchy sequence, completeness, etc. may as well be defined accordingly in $b$-metric spaces.

Kannan's fixed point theorem got its due attention and some authors gave an attempt to extend his result (refer to [15], [20], [25], [26], [31]). In this paper, we also try to extend the result of Kannan using the following class of subadditive altering distance functions.

Definition 1.2. A function $\phi:[0, \infty) \longrightarrow[0, \infty)$ is said to be a subadditive altering distance function if

(i) $\phi$ is an altering distance function [15], (i.e., $\phi$ is continuous, strictly increasing and $\phi(t)=0$ if and only if $t=0$ )

(ii) $\phi(x+y) \leq \phi(x)+\phi(y) \quad \forall x, y \in[0, \infty)$ 
Example 2. It can be easily seen that the functions $\phi_{1}(x)=k x$ for some $k \geq 1, \phi_{2}(x)=\sqrt[n]{x}, n \in \mathbf{N}, \phi_{3}(x)=\log (1+x), x \geq 0$ and $\phi_{4}(x)=\tan ^{-1} x$ are such subadditive altering distance functions.

Here we note, if $\phi$ is sub-additive, then for any non-negative real number $k<1$

$$
\phi(d(x, y)) \leq k \phi(d(a, b)) \quad d(x, y) \leq k^{\prime} d(a, b)
$$

for some $k^{\prime}<1$.

\section{Main results}

Consider $\phi$ as a subadditive altering distance function and the $b$-metric $d$ is assumed to be continuous in the topology generated by it.

We derive some fixed point results among which one of them is a generalization of a result given by Górnicki in [17].

Theorem 2.1. Let $(X, d)$ be a complete $b$-metric space with coefficient $s \geq 1$ and let $T: X \longrightarrow X$ be a mapping such that there exists $p<\frac{1}{2 s+1}$ satisfying

$$
\phi(d(T x, T y)) \leq p\{\phi(d(x, y))+\phi(d(x, T x))+\phi(d(y, T y))\}
$$

for all $x, y \in X$. Then $T$ has an unique fixed point $z \in X$, and for any $x \in X$ the sequence of iterates $\left\{T^{n} x\right\}$ converges to $z$ and for $q=\frac{2 p}{1-p}<1$,

$$
d\left(T^{n+1} x, T^{n} x\right) \leq q^{n} d(x, T x), \quad n=0,1,2, \ldots
$$

Proof. For an arbitrary element $x \in X$, let $u=T x$. Then

$\phi(d(u, T u))=\phi(d(T x, T u)) \leq p\{\phi(d(x, u))+\phi(d(x, T x))+\phi(d(u, T u))\}$

that is,

$$
\phi(d(u, T u)) \leq q \phi(d(x, T x)) \quad \text { where } \quad q=\frac{2 p}{1-p}<1
$$

Thus

$$
d(u, T u) \leq q^{\prime} d(x, T x)
$$


for some $q^{\prime}<1$. Without loss of generality, we assume $q^{\prime}=q$.

Now, for an arbitrary point $x_{0} \in X$ consider the sequence $\left\{x_{n}\right\}$ where $x_{n+1}=T x_{n}, n=0,1,2, \ldots \quad$ For $m, n \in \mathbf{N}$ with $m>n$, we have $\mathrm{d}\left(\mathrm{x}_{n}, x_{m}\right) \leq s d\left(x_{n}, x_{n+1}\right)+s^{2} d\left(x_{n+1}, x_{n+2}\right)+\ldots+s^{m-n+1} d\left(x_{m-1}, x_{m}\right)$ $\leq d\left(T x_{0}, x_{0}\right)\left(s q^{n}+s^{2} q^{n+1}+\ldots+s^{m-n+1} q^{m}\right)$ $\leq q^{n-1} d\left(T x_{0}, x_{0}\right)\left(s q+(s q)^{2}+\ldots+(s q)^{m}\right)$ $\leq q^{n-1} d\left(T x_{0}, x_{0}\right) \frac{1}{1-s q}, \quad$ since $s q<1$

$\longrightarrow 0, \quad$ as $\quad n \rightarrow \infty$, showing that $\left\{x_{n}\right\}$ is a Cauchy sequence in $H$, which is complete. Therefore, there exists $z \in H$ such that

$$
\lim _{n \rightarrow \infty} x_{n}=z .
$$

Now, from (2.1) we get $\phi(d(T z, z)) \leq \phi\left(s d\left(T z, T x_{n}\right)+s^{2} d\left(T x_{n}, x_{n}\right)+s^{2} d\left(x_{n}, z\right)\right)$ $\leq s \phi\left(d\left(T z, T x_{n}\right)\right)+s^{2} \phi\left(d\left(T x_{n}, x_{n}\right)\right)+s^{2} \phi\left(d\left(x_{n}, z\right)\right)$ $\leq \operatorname{sp}\left\{\phi\left(d\left(z, x_{n}\right)\right)+\phi(d(z, T z))+\phi\left(d\left(x_{n}, T x_{n}\right)\right)\right\}$ $+s^{2} \phi\left(d\left(T x_{n}, x_{n}\right)\right)+s^{2} \phi\left(d\left(x_{n}, z\right)\right)$, or, $(1-s p) \phi(d(T z, z)) \leq\left(s p+s^{2}\right)\left\{\phi\left(d\left(z, x_{n}\right)\right)+\phi\left(d\left(T x_{n}, x_{n}\right)\right)\right\}$ $\leq\left(s p+s^{2}\right)\left\{\phi\left(d\left(z, x_{n}\right)\right)+\phi\left(q^{n} d\left(T x_{0}, x_{0}\right)\right)\right\}$ Since the above relation is true for all $n \in \mathbf{N}$ and $1-s p \neq 0$, we have

$$
\phi(d(T z, z)) \longrightarrow 0, \quad \text { as } n \rightarrow \infty,
$$

showing that $d(T z, z)=0$. To show the uniqueness of the fixed point $z$, let $w \in X$ be another fixed point of $T$. Then $\phi(d(z, w))=\phi(d(T z, T w)) \leq$ $p\{\phi(d(z, w))+\phi(d(z, T z))+\phi(d(w, T w))\}$

$\leq p \phi(d(z, w))$. Since $\phi$ is strictly increasing and $p<\frac{1}{2 s+1}$, this will be true iff $d(z, w)=0$.

Finally, from $(2.2)$ we have $\mathrm{d}\left(\mathrm{T}^{n+1} x, T^{n} x\right) \leq q d\left(T^{n-1} x, T^{n} x\right)$, where $q=$ $\frac{2 p}{1-p}<1$ that is,

$$
d\left(T^{n+1} x, T^{n} x\right) \leq q^{n} d(x, T x), \quad n=0,1,2, \ldots
$$

Example 3. Consider the complete $b$-metric space $(X, d)$ with $X=[0,1]$ and $d(x, y)=|x-y|$ for all $x, y \in X$. Let $T: X \longrightarrow X$ be given by $T x=\frac{x}{2}$ for all $x \in X$. Then for $\phi(t)=\sqrt{t}$, we have $\phi(d(T x, T y))<$ $\frac{1}{3}\{\phi(d(x, y))+\phi(d(x, T x))+\phi(d(y, T y))\}$ $\left|\frac{x}{2}-\frac{y}{2}\right|<\frac{1}{3}\left\{|x-y|+\left|x-\frac{x}{2}\right|+\left|y-\frac{y}{2}\right|\right\}$ $\frac{1}{6}|x-y|<\frac{1}{6}\{|x|+|y|\}$, which is true for all $x, y \in X$. Thus $T$ is a 
continuous map satisfying (2.1) and 0 is its fixed point, which is unique. Also, if $x_{0}$ is any point of $X$, then the sequence $\left\{T^{n} x_{0}\right\}=\left\{\frac{x_{0}}{2^{n}}\right\}$ converges to 0 .

Consider the function

$$
T x=\{x 2, \quad 0 \leq x<10, \quad x=1
$$

which has a discontinuity at $x=1$. Similar calculation shows that $T$ is a map satisfying (2.1) and 0 is its fixed point, which is unique. And if $x_{0}$ is any point of $X$, then the sequence $\left\{T^{n} x_{0}\right\}=\left\{\frac{x_{0}}{2^{n}}\right\}$ converges to 0 .

Corollary 2.2. Let $(X, d)$ be a complete $b$-metric space and $T: X \longrightarrow X$ be a mapping such that

$$
d(T x, T y) \leq p\{d(x, y)+d(x, T x)+d(y, T y)\} \quad \forall x, y \in X
$$

where $p<\frac{1}{2 s+1}$. Then $T$ has a unique fixed point $z \in X$ and for every $x_{0} \in X$, the sequence $\left\{T^{n} x_{0}\right\}$ converges to $z$.

Proof. The result follows from Theorem 2.1 on taking $\phi(x)=x, x \in X$.

Corollary 2.3. Let $(X, d)$ be a complete $b$-metric space and $T: X \longrightarrow X$ be a continuous mapping such that for some positive integer $k$

$$
\phi\left(d\left(T^{k} x, T^{k} y\right)\right) \leq p\left\{\phi(d(x, y))+\phi\left(d\left(x, T^{k} x\right)\right)+\phi\left(d\left(y, T^{k} y\right)\right)\right\}
$$

for some $p<\frac{1}{2 s+1}$ and for all $x, y \in X$. Then there exists an unique fixed point of $T$.

Proof. Applying Theorem 2.1 to the self mapping $S=T^{k}$, we get that $S$ has an unique fixed point, say $z$, so that $T^{k} z=S z=z$.

Since $T^{k+1} z=T z$,

$$
S T z=T^{k}(T z)=T^{k+1} z=T z,
$$

and so $T z$ is a fixed point of $S$. By the uniqueness of the fixed point of $S$, we get $T z=z$. Taking $\phi(x)=\log (1+x)$, we get the following result as a particular case of Theorem 2.1. 
Corollary 2.4. Let $(X, d)$ be a complete $b$-metric space and let $T$ : $X \longrightarrow X$ be a mapping such that for $p<\frac{1}{2 s+1}$, the relation

$$
\{1+d(T x, T y)\}^{\frac{1}{p}}<e(1+d(x, y))(1+d(x, T x))(1+d(y, T y))
$$

holds for all $x, y \in X$. Then $T$ has a unique fixed point $z \in X$, and for any $x \in X$ the sequence of iterates $\left\{T^{n} x\right\}$ converges to $z$ and for $q=\frac{2 p}{1-p}$,

$$
d\left(T^{n+1} x, T^{n} x\right) \leq q^{n} d(x, T x), \quad n=0,1,2, \ldots
$$

Example 4. Consider the b-metric space $(X, d)$, where $X=[0,1]$ and $d(x, y)=|x-y|^{2}$ for all $x, y \in X$. Define the mapping $T: X \longrightarrow X$ by

$$
T x=\frac{x}{k} \quad \forall x \in X
$$

for some $k \in \mathbf{N}$. Then $p<\frac{1}{5}$ and

$$
\{1+d(T x, T y)\}^{5}=\left(1+\frac{|x-y|^{2}}{k^{2}}\right)^{5} \leq\left(1+\frac{1}{k^{2}}\right)^{5}
$$

and

$$
e(1+d(x, y))(1+d(x, T x))(1+d(y, T y)) \geq e .
$$

Condition (2.3) is satisfied for $k \geq 3$ and by Corollary $2.4 T$ has an unique fixed point, which is 0 here. Moreover, for an arbitrary (but fixed) point $x_{0} \in X$, the sequence of iterates $\left\{\frac{x_{0}}{k^{n}}\right\}$ converges to the fixed point 0 .

On the other hand, if $d(x, y)=|x-y|$, then $T$ satisfies (2.3) for $k \geq 2$.

Theorem 2.5. $\quad$ Let $(X, d)$ be a complete b-metric space with coefficient $s \geq 1$ and let $T: X \longrightarrow X$ be a mapping such that there exists $p_{1}, p_{2}, p_{3}$ with $p_{1}+p_{2}+p_{3}<1$ and $s p_{2}<1$ satisfying

$$
\phi(d(T x, T y)) \leq p_{1} \phi(d(x, y))+p_{2} \phi(d(x, T x))+p_{3} \phi(d(y, T y))
$$

for all $x, y \in X$. Then $T$ has a unique fixed point $z \in X$, and for any $x \in X$ the sequence of iterates $\left\{T^{n} x\right\}$ converges to $z$ and for $q=\frac{p_{1}+p_{2}}{1-p_{3}}<1$,

$$
d\left(T^{n+1} x, T^{n} x\right) \leq q^{n} d(x, T x), \quad n=0,1,2, \ldots
$$


Proof. The proof is similar to the proof of Theorem 2.1. On considering $(X, d)$, a metric space and $\phi(x)=x$ in the above result, we get the result given in [17] as a particular case.

Following [16], we get a characterization for the completeness of $(X, d)$ using the mapping $T$, with the help of the the properties of the subadditive altering distance function $\phi$.

Theorem 2.6. $\quad$ For a $b$-metric space $(X, d)$, if every mapping $T: X \longrightarrow$ $X$ satisfying (2.1) for some $0 \leq p<\frac{1}{2 s+1}$ has an unique fixed point, then $X$ is complete.

It is worth mentioning that if $(X, d)$ is a complete $b$-metric space and $T$ is a self map on $X$ such that for some $0 \leq p<\frac{1}{2 s+1}$

$$
\phi(d(T x, T y)) \leq p\{\phi(d(x, T x))+\phi(d(y, T y))\} \quad \forall x, y \in X
$$

then from Theorem 2.1, $T$ has a unique fixed point $z \in X$ and for every $x_{0} \in X$, the sequence $\left\{T^{n} x_{0}\right\}$ converges to $z$.

Following the proof of Theorem 2.1, we get the following result and derive the Kannan fixed point theorem as a consequence.

Theorem 2.7. Let $(X, d)$ be a complete $b$-metric space and let $T: X \longrightarrow$ $X$ be a mapping such that there exists $p<\frac{1}{2 s}$ satisfying

$$
\phi(d(T x, T y)) \leq p\{\phi(d(x, T x))+\phi(d(y, T y))\}
$$

for all $x, y \in X$. Then $T$ has a unique fixed point $z \in X$, and for any $x \in X$ the sequence of iterates $\left\{T^{n} x\right\}$ converges to $z$ and for $q=\frac{p}{1-p}<1$,

$$
d\left(T^{n+1} x, z\right) \leq q^{n} d(x, T x), \quad n=0,1,2, \ldots
$$

We note that when $(X, d)$ is a complete metric space and $\phi(x)=x$ in the above theorem, we get Theorem 1.1, the Kannan fixed point theorem.

Example 5. Consider the complete b-metric space $(X, d)$ where

$$
X=[0,1] \cup[2, \infty) \quad \text { and } \quad d(x, y)=\{\min \{x+y, 2\}, x \neq y 0, \quad x=y
$$


If $\phi(t)=\log (1+t)$, then condition (2.5) reduces to

$$
\{1+d(T x, T y)\}^{2}<e\{1+d(x, T x)\}\{1+d(y, T y)\}
$$

Let $T: X \longrightarrow X$ be defined by

$$
T x=\left\{12, \quad 0 \leq x \leq 1 \frac{1}{2}-\frac{1}{x}, \quad x \geq 2\right.
$$

If $x, y \in[0,1]$, then (2.6) is trivially satisfied.

For $2<x<y$, we have

$$
[1+d(T x, T y)]^{2}=\left[1+\min \left\{1-\frac{1}{x}-\frac{1}{y}, 2\right\}\right]^{2}<4
$$

and

$$
e\{1+d(x, T x)\}\{1+d(y, T y)\} \geq 9 e .
$$

When $x \in[0,1]$ and $y \geq 2$, then

$$
[1+d(T x, T y)]^{2}=\left[1+\min \left\{1-\frac{1}{y}, 2\right\}\right]^{2}<4
$$

and

$$
e\{1+d(x, T x)\}\{1+d(y, T y)\}=3 e\left(1+x+\frac{1}{2}\right) \geq \frac{9}{2} e .
$$

Thus $T$ satisfies (2.6) and by Theorem 2.7, $T$ has a unique fixed point which in this case is $x=\frac{1}{2}$. For an arbitrary $x_{0} \in X$, the sequence of iterates $\left\{T^{n} x_{0}\right\}$ converges to $\frac{1}{2}$. In fact, $T^{2} x=\frac{1}{2}$ for all $x \in X$.

We note that $s=1, p<\frac{1}{2}$ and $s p<1$. If we consider the $b$-metric defined by

$$
d(x, y)=\left\{\min \{x+y, 2\}^{2}, \quad x \neq y 0, \quad x=y\right.
$$

then $s=2$ and we still have $s p<1$. Similar calculation shows that $T$ satisfies the conditions of Theorem 2.7 and we get the result.

Theorem 2.8. For a $b$-metric space $(X, d)$, if every mapping $T: X \longrightarrow$ $X$ satisfying (2.5) for some $p<\frac{1}{2 s}$ has a unique fixed point, then $X$ is complete. 
Proof. Following the proof of Theorem 2.6, we get the result.

Remark 1. Since sequentially compact b-metric spaces are complete, the completeness condition in Theorem 2.7 may be replaced by sequential compactness.

\section{Boundedly compactness and $T$-orbital compactness of $X$}

A boundedly compact metric space ([14], [16]) is a metric space $X$ in which every bounded sequence in $X$ has a convergent subsequence. The same notion may be defined in the case of $b$-metric spaces. The class of boundedly compact $b$-metric spaces is larger than that of sequentially compact spaces as the the $b$-metric space $\mathbf{R}$ of real numbers with the usual metric is not sequentially compact but boundedly compact. In the next result $p$ is independent of the coefficient $s$ of the $b$-metric space.

Theorem 2.9. Let $(X, d)$ be a boundedly compact b-metric space and $T: X \longrightarrow X$ be a continuous mapping satisfying (2.5) for some $0 \leq p<\frac{1}{2}$. Then $T$ has a unique fixed point $z \in X$ and for every $x_{0} \in X$, the sequence $\left\{T^{n} x_{0}\right\}$ converges to $z$.

Proof. Let $x_{0}$ be an arbitrary point of $X$. Consider the iterated sequence $\left\{x_{n}\right\}$, where $x_{n}=T^{n} x_{0}$ for every $n \in \mathbf{N}$. We denote $d\left(x_{n}, x_{n+1}\right)$ by $\lambda_{n}$ and suppose that $\lambda_{n}>0$ for all $n \in \mathbf{N}$. Then using (2.5), we have $\phi\left(\lambda_{n}\right)=$ $\phi\left(d\left(T^{n} x_{0}, T^{n+1} x_{0}\right)\right)=\phi\left(d\left(T\left(T^{n-1} x_{0}\right), T\left(T^{n} x_{0}\right)\right)\right)$

$\leq p\left\{\phi\left(d\left(T^{n-1} x_{0}, T^{n} x_{0}\right)\right)+\phi\left(d\left(T^{n} x_{0}, T^{n+1} x_{0}\right)\right)\right\}$

$=p \phi\left(\lambda_{n-1}\right)+p \phi\left(\lambda_{n}\right)$ This implies

$$
(1-p) \phi\left(\lambda_{n}\right)<p \phi\left(\lambda_{n-1}\right) \quad \forall n \in \mathbf{N} .
$$

Since $1-p \geq p$, it follows that

$$
\lambda_{n}<\lambda_{n-1} \quad \forall n \in \mathbf{N}
$$

showing that the sequence $\left\{\lambda_{n}\right\}$ of positive real numbers is strictly decreasing sequence and hence convergent, say,

$$
\lim _{n \rightarrow \infty} \lambda_{n}=\lambda
$$


Now, for $m, n \in \mathbf{N}$ with $n<m$, we have $\phi\left(d\left(x_{m}, x_{n}\right)\right) \leq p\left\{\phi\left(d\left(x_{m-1}, x_{m}\right)+\right.\right.$ $\phi\left(d\left(x_{n-1}, x_{n}\right)\right\}$ $=p\left\{\phi\left(\lambda_{m-1}\right)+\phi\left(\lambda_{n-1}\right)\right\}$. As $m, n \rightarrow \infty$, we have

$$
\phi\left(d\left(x_{m}, x_{n}\right)\right) \leq \phi(\lambda) .
$$

This implies $d\left(x_{m}, x_{n}\right) \leq \lambda$ as $m, n \rightarrow \infty$, showing that $\left\{x_{n}\right\}$ is a bounded sequence. Therefore, $\left\{x_{n}\right\}$ has a subsequence which converges to, say, $z$, i.e.,

$$
\lim _{k \rightarrow \infty} x_{n_{k}}=z
$$

By the continuity of $T$, we have

$$
T z=T\left(\lim _{k \rightarrow \infty} T^{n_{k}} x_{0}\right)=\lim _{n \rightarrow \infty} T^{n_{k}+1} x_{0}=z,
$$

which proves $z$ is a fixed point of $T$.

Finally, if $w$ is another fixed point of $T$, then $\phi(d(z, w))=\phi(d(T z, T w))$ $\leq p\{\phi(d(z, w))+\phi(d(z, T z))+\phi(d(w, T w))\}$, that is,

$$
(1-p) \phi(d(z, w)) \leq 0
$$

which shows $z=w$, and thus $z$ is the unique fixed point of $T$.

Example 6. Consider the boundedly compact b-metric space $(X, d)$, where $X=[0, \infty)$ and

$$
d(x, y)=\{x+y, \quad x \neq y 0, \quad x=y
$$

Define $T: X \longrightarrow X$ by

$$
T x=\left\{12, \quad 0 \leq x \leq 2 \frac{1}{x}, \quad x>2\right.
$$

For $\phi(t)=t$, we have condition (2.5) as

$$
d(T x, T y)<\frac{1}{2}\{d(x, T x)+d(y, T y)\} .
$$

Now, for $x \neq y$ and $x, y>2$, we have

$$
d(T x, T y)=\frac{1}{x}+\frac{1}{y}<1
$$


and

$$
\frac{1}{2}\{d(x, T x)+d(y, T y)\}=\frac{1}{2}\left\{x+\frac{1}{x}+y+\frac{1}{y}\right\} \geq 2 .
$$

Again, for $0 \leq x \leq 2$ and $y>2$, we have

$$
d(T x, T y)=\frac{1}{2}+\frac{1}{y}<1
$$

and

$$
\frac{1}{2}\{d(x, T x)+d(y, T y)\}=\frac{1}{2}\left\{x+\frac{1}{2}+y+\frac{1}{y}\right\}>1 .
$$

Thus $T$ satisfies (2.8) and by Theorem 2.9, $T$ has a unique fixed point which is $x=\frac{1}{2}$. Since $T^{2} x=\frac{1}{2}$, we see that for every $x_{0} \in X$, the sequence of iterates $\left\{T^{n} x_{0}\right\}$ converges to $\frac{1}{2}$.

Garai et al. [16] defined T-orbitally compact metric spaces and derived a fixed point result for the same. The definition of $T$-orbitally compactness can be extended to $b$-metric spaces as follows.

Definition 2.1. $[16]$ Let $(X, d)$ be a $b$-metric space and $T$ be a self mapping on $X$. The orbit of $T$ at the point $x \in X$ is defined as the set

$$
O_{x}(T)=\left\{x, T x, T^{2} x, T^{3} x, \ldots\right\}
$$

and $X$ is said to be T-orbitally compact if every sequence in $O_{x}(T)$ has a convergent subsequence for all $x$ in $X$.

As mentioned by Garai et al. [16] a $T$-orbitally compact metric space need not be complete. For more details of $T$-orbitally compact metric spaces one may refer to Garai et al. [16].

Theorem 2.10. Let $(X, d)$ be a $T$-orbitally compact b-metric space with $T$ satisfying (2.5) with $p<\frac{1}{2}$ and $s p<1$. Then $T$ has a unique fixed point $w$ and for every $x \in X$,

$$
\lim _{n \rightarrow \infty} T^{n} x=w
$$


Proof. Let $x_{0} \in X$ be arbitrarily chosen but fixed, and consider the sequence $\left\{x_{n}\right\}$, where $x_{n}=T^{n} x_{0}$ for all $n \in \mathbf{N}$. Denoting $d\left(x_{n}, x_{n+1}\right)$ by $\mu_{n}$, we have from $(2.5)$

$$
\phi\left(\mu_{n}\right) \leq p\left\{\phi\left(\mu_{n-1}\right)+\phi\left(\mu_{n}\right)\right\}
$$

and since $\phi$ is strictly increasing and $p<\frac{1}{2}$, we get

$$
\mu_{n}<\mu_{n-1}
$$

which shows that the sequence $\left\{\mu_{n}\right\}$ of non-negative real numbers is a decreasing sequence and hence convergent. Since $X$ is $T$-orbitally compact, $\left\{x_{n}\right\}$ has a convergent subsequence, $\left\{x_{n_{k}}\right\}$, which converges to, $w \in X$, say. Now,

$$
\lim _{n \rightarrow \infty} \mu_{n_{k}}=\lim _{n \rightarrow \infty} d\left(x_{n_{k}}, x_{n_{k}+1}\right)=d\left(\lim _{n \rightarrow \infty} x_{n_{k}}, \lim _{n \rightarrow \infty} x_{n_{k}+1}\right)=d(z, z)=0 .
$$

This shows that the convergent sequence $\left\{\mu_{n}\right\}$ contains a subsequence $\left\{\mu_{n_{k}}\right\}$ which converges to 0 and therefore

$$
\lim _{n \rightarrow \infty} \mu_{n}=0 .
$$

For every $m, n \in \mathbf{N}$, we have $\phi\left(d\left(x_{n}, x_{m}\right)\right) \leq p\left\{\phi\left(d\left(T^{n-1} x, T^{n} x\right)\right)+\right.$ $\left.\phi\left(d\left(T^{m-1} x, T^{m} x\right)\right)\right\}$

$=p\left\{\phi\left(\mu_{n-1}\right)+\phi\left(\mu_{m-1}\right)\right\}$

$\longrightarrow 0 \quad$ as $\quad n, m \rightarrow \infty$. This implies

$$
d\left(x_{n}, x_{m}\right) \longrightarrow 0 \quad \text { as } \quad n, m \rightarrow \infty
$$

showing that $\left\{x_{n}\right\}$ is a Cauchy sequence, and therefore

$$
\lim _{n \rightarrow \infty} x_{n}=w .
$$

Now, $\phi(d(w, T w)) \leq \phi\left(s d\left(w, T^{n+1} x\right)+s d\left(T^{n+1} x, T w\right)\right)$

$\leq s \phi\left(d\left(w, x_{n+1}\right)\right)+\operatorname{sp}\left\{\phi\left(d\left(x_{n}, x_{n+1}\right)\right)+\phi(d(w, T w))\right\}$ that is, (1-sp) $\phi(d(w, T w)) \leq$ $s \phi\left(d\left(w, x_{n+1}\right)\right)+\operatorname{sp\phi }\left(d\left(x_{n}, x_{n+1}\right)\right)$

$\longrightarrow 0 \quad$ as $\quad n \rightarrow \infty$ which implies $d(w, T w)=0$, establishing that $w$ is a fixed point of $T$. The uniqueness of the fixed point is derived from condition (2.5) and the monotonicity of $\phi$. 
Example 7. Consider the incomplete $b$-metric space $(X, d)$, where $X=$ $(0, \infty)$ and

$$
d(x, y)=\{x+y, x \neq y 0, \quad x=y
$$

Define $T: X \longrightarrow X$ by

$$
T x=\left\{12, \quad 0<x<21, \quad x=2 \frac{1}{x}, \quad x>2\right.
$$

It can be easily seen that $T$ is not continuous and $X$ is $T$-orbitally compact. For $\phi(x)=\log (1+x)$, we have condition (2.5) as

$$
\{1+d(T x, T y)\}^{2}<e\{1+d(x, T x)\}\{1+d(y, T y)\}
$$

For $x, y>2$, we have

$$
\begin{gathered}
\{1+d(\text { Tx }, T y)\}^{2}=\left\{1+\frac{1}{x}+\frac{1}{y}\right\}^{2}<4, \\
e\{1+d(x, T x)\}\{1+d(y, T y)\}=e\left\{1+x+\frac{1}{x}\right\}\left\{1+y+\frac{1}{y}\right\} \geq 9 e .
\end{gathered}
$$

For $0<x<2$ and $y>2$, we have

$$
\begin{gathered}
\{1+d(T x, T y)\}^{2}=\left\{1+\frac{1}{2}+\frac{1}{y}\right\}^{2}<4, \\
e\{1+d(x, T x)\}\{1+d(y, T y)\}=e\left\{1+x+\frac{1}{2}\right\}\left\{1+y+\frac{1}{y}\right\}>4 e .
\end{gathered}
$$

For $0<x<2$ and $y=2$, we have

$$
\begin{gathered}
\{1+d(T x, T 2)\}^{2}=\left\{1+\frac{1}{2}+1\right\}^{2}=\frac{25}{4}<6, \\
e\{1+d(x, T x)\}\{1+d(2, T 2)\}=e\left\{1+x+\frac{1}{2}\right\}\{1+2+1\} \geq 6 e .
\end{gathered}
$$

For $x>2$ and $y=2$, we have

$$
\begin{gathered}
\{1+d(T x, T 2)\}^{2}=\left\{1+\frac{1}{x}+1\right\}^{2}<6, \\
e\{1+d(x, T x)\}\{1+d(2, T 2)\}=e\left\{1+x+\frac{1}{2}\right\}\{1+2+1\}>12 e .
\end{gathered}
$$

Thus $T$ satisfies condition (2.5) and therefore, by Theorem 2.10, $T$ has a unique fixed point, $x=\frac{1}{2}$. Also, for an arbitrary $x_{0} \in X$, it is easily seen that $T^{2} x_{0}=\frac{1}{2}$ so that the sequence of iterates $\left\{T^{n} x_{0}\right\}$ converge to the fixed point $x=\frac{1}{2}$. 


\section{Asymptotic regularity of $T$}

In the previous section, Theorem 2.7 does not hold for $p \geq \frac{1}{2}$. Here, we try to raise the bound of $p$ by assuming $T$ to be an asymptotically regular mapping. For a metric space $(X, d)$, a mapping $T: X \longrightarrow X$ is called asymptotically regular [7] if

$$
\lim _{n \rightarrow \infty} d\left(T^{n} x, T^{n+1} x\right)=0 \quad \text { for all } \quad x \in X .
$$

For further details in asymptotic regular mappings we refer to $[3,8]$ and the references therein.

Theorem 2.11. Let $(X, d)$ be a complete $b$-metric space and $T: X \longrightarrow$ $X$ be an asymptotically regular map satisfying (2.5) for some $p$ with $s p<1$. Then $T$ has a unique fixed point.

Proof. Let $x \in X$ and consider the sequence $\left\{x_{n}\right\}$ where $x_{n}=T^{n} x, n \in$ $\mathbf{N}$. For $m>n$, since $T$ is asymptotically regular $\phi\left(d\left(T^{n+1} x, T^{m+1} x\right)\right) \leq$ $p\left\{\phi\left(d\left(T^{n} x, T^{n+1} x\right)\right)+\phi\left(d\left(T^{m}, T^{m+1}\right)\right)\right\}$

$\longrightarrow 0 \quad$ as $n \rightarrow \infty$ Thus

$$
d\left(T^{n+1} x, T^{m+1} x\right) \longrightarrow 0 \quad \text { as } n \rightarrow \infty
$$

showing that the sequence $\left\{x_{n}\right\}$ is a Cauchy sequence. Since $X$ is complete, there exists $z \in X$ such that $\lim _{n \rightarrow \infty} T^{n} x=z$.

Again, $\phi(d(z, T z)) \leq \phi\left(s d\left(z, T^{n+1} x\right)+s d\left(T^{n+1} x, T z\right)\right)$

$\leq s \phi\left(d\left(z, T^{n+1} x\right)\right)+s \phi\left(d\left(T^{n+1} x, T z\right)\right)$

$\leq s \phi\left(d\left(z, T^{n} x\right)\right)+s p\left\{\phi\left(d\left(T^{n} x, T^{n+1} x\right)\right)+\phi(d(z, T z))\right\}$ That is,

$$
(1-s p) \phi(d(z, T z)) \leq s \phi\left(d\left(z, T^{n} x\right)\right)+\operatorname{sp} \phi\left(d\left(T^{n} x, T^{n+1} x\right)\right) .
$$

Therefore, in the limiting case when $n \rightarrow \infty$, we have

$$
(1-s p) \phi(d(z, T z))=0 \quad d(z, T z)=0 .
$$

Suppose that $T w=w$ with $z \neq w$. Then

$$
\phi(d(T z, T w)) \leq p\{\phi(d(z, T z))+\phi(d(w, T w))\}=0
$$


implying $T z=T w$. But then we have

$$
w=T w=T z=z,
$$

a contradiction.

Example 8. Consider the complete $b$-metric space $(X, d)$ where $X=$ $[0,1]$ and $d$ is the usual metric on $X$. It can be easily seen that the function $T: X \longrightarrow X$ defined by $T x=\frac{x}{2}$ for all $x \in X$ is asymptotically regular. Since $s=1$, we can take $p<1$. Then for $\phi(t)=\log (1+t)$, condition (2.5) reduces to

$$
1+d(T x, T y)<e\{1+d(x, T x)\}\{1+d(y, T y)\}
$$

But we have, $1+d(T x, T y)=1+\left|\frac{x}{2}-\frac{y}{2}\right| \leq 1+\left|\frac{x}{2}\right|+\left|\frac{y}{2}\right| \leq\left\{1+\left|\frac{x}{2}\right|\right\}\left\{1+\left|\frac{y}{2}\right|\right\}$ $\leq e\{1+d(x, T x)\}\{1+d(y, T y)\}$. By the above theorem, there exists a unique fixed point. Here, $x=0$ is the unique fixed point.

If we consider the $b$-metric $d(x, y)=|x-y|^{2}$, then $s=2$ and $p<\frac{1}{2}$. Condition (2.5) in this case is

$$
\{1+d(T x, T y)\}^{2}<e\{1+d(x, T x)\}\{1+d(y, T y)\}
$$

and is satisfied by $T$ and we get the same result as before.

Theorem 2.12. Let $(X, d)$ be a complete $b$-metric space and $T: X \longrightarrow$ $X$ be an asymptotically regular map satisfying (2.1) for some $p$ with $s p<1$. Then $T$ has a unique fixed point.

Proof. Let $x \in X$ and consider the sequence $\left\{x_{n}\right\}$ where $x_{n}=T^{n} x, n \in$ $\mathbf{N}$. For $m>n$, since $T$ is asymptotically regular, we have $\phi\left(d\left(T^{n+1} x, T^{m+1} x\right)\right) \leq$ $p\left\{\phi\left(d\left(T^{n} x, T^{m} x\right)\right)+\phi\left(d\left(T^{n} x, T^{n+1} x\right)\right)\right.$ $\left.+\phi\left(d\left(T^{m} x, T^{m+1} x\right)\right)\right\}$ $\leq k p\left\{\phi\left(d\left(T^{n} x, T^{n+1} x\right)\right)+\phi\left(d\left(T^{m} x, T^{m+1} x\right)\right)\right\}$ $p \phi\left(d\left(T^{n+1} x, T^{m+1} x\right)\right)$, for some positive integer $k$, and so, $\phi\left(d\left(T^{n+1} x, T^{m+1} x\right)\right) \leq$ $\frac{k p}{1-p}\left\{\phi\left(d\left(T^{n} x, T^{n+1} x\right)\right)+\phi\left(d\left(T^{m} x, T^{m+1} x\right)\right)\right\}$ 
$\longrightarrow 0$ as $n \rightarrow \infty$, which shows that $\left\{T^{n} x\right\}$ is a Cauchy sequence. Since $X$ is complete, there exists $z \in X$ such that

$$
\lim _{n \rightarrow \infty} T^{n} x=z
$$

Now, $\phi(d(z, T z)) \leq \phi\left(s d\left(z, T^{n+1} x\right)+s d\left(T^{n+1} x, T z\right)\right)$

$\leq s \phi\left(d\left(z, T^{n+1} x\right)\right)+\operatorname{sp}\left\{\phi\left(d\left(T^{n} x, z\right)\right)+\phi\left(d\left(T^{n} x, T^{n+1} x\right)\right)\right.$

$+\phi(d(z, T z))\}$ or, $\quad(1$-sp $) \phi(d(z, T z)) \leq s \phi\left(d\left(z, T^{n+1} x\right)\right)$

$+\operatorname{sp}\left\{\phi\left(d\left(T^{n} x, z\right)\right)+\phi\left(d\left(T^{n} x, T^{n+1} x\right)\right)\right\}$

$\longrightarrow 0 \quad$ as $\quad n \rightarrow \infty$. Hence $d(z, T z)=0$, that is, $z$ is a fixed point of $T$. If possible, let $w \neq z$ with $T w=w$. Then $\phi(d(T w, T z)) \leq p\{\phi(d(w, z))+$ $\phi(d(w, T w))+\phi(d(z, T z))\}$

$<\phi(d(w, z))$ which is a contradiction. Hence the result. As pointed

out by Górnicki in [17], a mapping $T: X \longrightarrow X$ satisfying

$$
\phi(d(T x, T y))<\phi(d(x, T x))+\phi(d(y, T y))
$$

for all $x, y \in X$ with $x \neq y$, and asymptotically regular may not have a fixed point (one may refer to Example 3.2 of [17]).

\section{Acknowledgement}

The authors are grateful to the referee for his valuable comments.

\section{References}

[1] S. Agarwal, K. Qureshi and J. Nema, "A fixed point theorem for bmetric space", International journal of pure and applied mathematical sciences, vol. 9, no. 1, pp. 45-50, 2016. [On line]. Available: https://bit.ly/20YMcad

[2] T. An, N. Dung and V. Hang, "General fixed point theorems on metric spaces and 2-metric spaces", Filomat, vol. 28, no. 10, pp. 2037-2045, 2014, doi: 10.2298/FIL1410037A. 
[3] J. Baillon, R. Bruck and S. Reich, "On the asymptotic behaviour of non-expansive mappings and semi-groups in Banach spaces", Houston Journal of mathematics, 4, pp. 1-9, 1978. [On line]. Available: https://bit.ly/35QmEBU

[4] I. Bakhtin, "The contraction mapping principle in almost metric spaces", Funct. Anal., 30, pp. 26-37, 1989.

[5] S. Banach, "Sur les opérations dans les ensembles abstraits et leur application aux équations intégrales", Fundamenta mathematicae, vol. 3, no. 1, pp. 133-181, 1922. [On line]. Available: https://bit.ly/2Br6H7t

[6] M. Boriceanu, "Fixed point theory for multivalued generalized contraction on a set with two b-metrics", Studia universitatis Babeș-Bolyai mathematica, vol. 54, no. 3, pp. 3-14, 2009. [On line]. Available: https://bit.ly/2J4xf2B

[7] F. Browder and W. Peryshyn, "The solution by iteration of nonlinear functional equations in Banach spaces", Bulletin of the american mathematical society, vol. 72, no. 3, pp. 571-575, 1966. [On line]. Available: https://bit.ly/2P1jUM9

[8] R. Bruck and S. Reich, "Nonexpansive projections and resolvents of accretive operators in Banach spaces", Houston journal of mathematics, vol. 3, no. 4, pp. 459-470, 1977. [On line]. Available: https://bit.ly/2P2zE1m

[9] S. Czerwik, "Contraction mappings in b-metric spaces", Acta mathematica et informatica universitatis ostraviensis, vol. 1, no. 1, pp. 5-11, 1993. [On line]. Available: https://bit.ly/32vRePo

[10] D. Das and N. Goswami, "Fixed points of different contractive type mappings on tensor product spaces", International journal of innovative research in science, engineering and technology, vol. 3, no. 7, pp. 14512-14519, 2014. [On line]. Available: https://bit.ly/35M4fX2

[11] D. Das and N. Goswami, "Fixed points of mappings satisfying a weakly contractive type condition", Journal of mathematical research with applications, vol. 36, no. 1, pp. 70-78, 2016, doi: 10.3770/j.issn:2095-2651.2016.01.009

[12] D. Das and N. Goswami, "Some fixed point theorems on the sum and product of operators in tensor product spaces", International journal of pure and applied mathematics, vol. 109, no. 3, pp. 651663, 2016, doi: 10.12732/ijpam.v109i3.13.

[13] D. Das, N. Goswami and V. Mishra, "Some results on fixed point theorems in Banach algebras", International journal of analysis and applications, vol. 13, no. 1, pp. 32-40, 2017.

[14] R. Edwards, Functional analysis: theory and applications. New York, NY: Holt, Rinehart and Winston, 1965. 
[15] H. Faraji and K. Nourouzi, "A generalization of Kannan and Chatterjea fixed point theorems in complete $b$-metric spaces", Sahand communications in mathematical analysis, vol. 6, no. 1, pp. 77-86, 2017, doi: 10.22130/SCMA.2017.23831

[16] H. Garai, T. Senapati and L. Dey, "A study on Kannan type contraction mapping", Jul. 2017. arXiv:1707.06383v1.

[17] J. Górnicki, "Fixed point theorems for Kannan type mappings", Journal of fixed point theory and applications, vol. 19, no. 3, pp. 2145-2152, 2017, doi: 10.1007/s11784-017-0402-8.

[18] N. Hussain, D. Dorić, Z. Kadelburg and S. Radenović, "Suzuki-type fixed point results in metric type spaces", Fixed point theory and applications, vol. 2012, Article ID 126, 2012, doi: 10.1186/16871812-2012-126.

[19] M. Jovanović, Z. Kadelburg, S. Radenović, “Common fixed point results in metric-type spaces", Fixed point theory and applications, vol. 2010, Article ID 978121, 2010, doi: $10.1155 / 2010 / 978121$.

[20] Z. Kadelburg, L. Paunovic and S. Radenovic, "A note on fixed point theorems for weakly T-Kannan and T -Chatterjea contractions in b-metric spaces", Gulf journal of mathematics, vol. 3, no. 3, pp. 57-67, 2015. [On line]. Available: https://bit.ly/2oMX5kU

[21] R. Kannan, "Some results on fixed points", Bulletin of calcutta mathematical society, 60, pp. 71-76, 1968.

[22] M. Khamsi, "Remarks on cone metric spaces and fixed point theorems of contractive mappings", Fixed point theory and applications, 2010, Article ID 315398 2010, doi: 10.1155/2010/315398.

[23] M. Kir and H. Kiziltune, "On some well known fixed point theorems in b-metric space", Turkish journal of analysis and number theory, vol. 1, no. 1, pp. 13-16, 2013, doi: 10.12691/tjant-1-1-4.

[24] S. Mohanta, "Coincidence points and common fixed points for expansive type mappings in b-metric spaces", Iranian journal of mathematical sciences and informatics, vol. 11, no. 1, pp. 101113, 2016, doi: 10.7508/ijmsi.2016.01.009.

[25] S. Moradi, "New extensions of Kannan fixed point theorem on complete metric and generalized metric spaces", International journal of mathematical analysis, vol. 5, no. 47, pp. 2313-2320, 2011. [On line]. Available: https://bit.ly/2MvzdLG

[26] R. Pant and R. Panicker, "Geraghty and Ćirić type fixed point theorems in b-metric spaces", Journal of nonlinear sciences and applications, vol. 9, no. 11, pp. 5741-5755, 2016, doi: 10.22436/jnsa.009.11.03. 
[27] J. Roshan, V. Parvaneh, S. Sedghi, N. Shobkolaei and W. Shatanawi, "Common fixed points of almost generalized ( $\psi$, $\phi)$ s-contractive mappings in ordered b-metric spaces", Fixed point theory and applications, 2013, Article ID 159, 2013, doi: 10.1186/1687-1812-2013-159.

[28] W. Sintunavarat, S. Plubtieng and P. Katchang, "Fixed point result and applications on b-metric space endowed with an arbitrary binary relation", Fixed point theory applications, 2013, Article ID 296, 2013, doi: 10.1186/1687-1812-2013-296.

[29] V. Subrahmanyam, "Completeness and fixed points", Monatshefte für mathematik, vol. 80, no. 4, pp. 325-330, 1975, doi: 10.1007/BF01472580.

[30] B. Tripathy, S. Paul and N. Das, "A fixed point theorem in a generalized fuzzy metric space", Boletim da sociedade paranaense de matematica, vol. 32, no. 2, pp. 221-227, 2014, doi: 10.5269/bspm.v32i2.20896.

[31] B. Tripathy, S. Paul and N. Das, "Banach's and Kannan's fixed point results in fuzzy 2-metric spaces", Proyecciones (Antofagasta, En línea), vol. 32, no. 4, pp. 359-375, 2013, doi: 10.4067/S0716-09172013000400005. 